\title{
Genetic structure of Siberian lemmings (Lemmus sibiricus) in a continuous habitat: large patches rather than isolation by distance
}

\author{
DOROTHEE EHRICH* \& NILS CHR. STENSETH \\ Division of Zoology, Department of Biology, University of Oslo, PO Box 1050, Blindern, N-0316 Oslo, Norway
}

\begin{abstract}
In a continuous habitat, restricted dispersal and local genetic drift are likely to create a pattern of increasing genetic differentiation with distance. Here, we describe the genetic structure of Siberian lemming (Lemmus sibiricus) populations in a continuous tundra habitat on the western coast of the Taimyr Peninsula, in order to determine the spatial scale at which genetic differentiation and isolation by distance occur. Sampling was carried out at three different geographical scales: (1) a continuous $11 \mathrm{~km}$ transect; (2) localities 10-30 km apart; and (3) two localities at 300 and $600 \mathrm{~km}$ from the main study area. Two types of genetic markers were used: partial sequences of the mitochondrial DNA control region and four microsatellite loci. On this basis the study populations were genetically quite homogeneous within patches extending over $8 \mathrm{~km}$ or more. Contrary to theoretical predictions, no pattern of isolation by distance among patches could be identified. This observation was interpreted as representing populations in migration-drift disequilibrium after a recent major mixing event. The lack of concordance between mtDNA haplotype phylogeny and the geographical distribution of haplotypes supported this interpretation. Spatial autocorrelation among individual genotypes on a local scale was weak and observed only in females, indicating a considerable amount of mostly malemediated gene flow. Average gene flow per generation was estimated to be in the range of several hundred metres.
\end{abstract}

Keywords: continuous habitat, gene flow, isolation by distance, Lemmus sibiricus, nonequilibrium population, recent colonization.

\section{Introduction}

In a fragmented habitat with restricted migration, genetic drift will, together with natural selection and mutation, lead to local genetic differentiation. In a continuous habitat, however, where no obvious fragmentation seems to prevent individual movement, genetic differentiation can also be present. Genetic drift occurs locally and may create genetic structure, a process called 'isolation by distance' (Wright, 1943). Dispersal among neighbouring clusters of related individuals leads to local gene flow, a process approximated by the stepping-stone model (Kimura \& Weiss, 1964). The resulting pattern of local similarity and increasing differentiation with distance can, over considerable periods of time, extend to large geographical areas. At such large distances, historical events such as population bottlenecks, range expansion or colonization may, in

*Correspondence. E-mail: dorothee@bio.uio.no addition to individual movement, shape the observable spatial structure (e.g. Avise, 1994). Here, we investigate the genetic structure of an abundant population of Siberian lemmings (Lemmus sibiricus Kerr 1792) living in a continuous habitat. Specifically, we ask to what extent the 'isolation-by-distance' model is appropriate for understanding the processes generating the observed spatial structure.

The choice of sampling units is crucial in order to investigate population structures, and may influence the conclusions of a study. No natural habitat is truly continuous, and at some scale a patchy distribution of individuals will typically be observed. It may, however, be difficult to define discrete subunits. The genetic structure of populations in approximately continuous habitats has been described for a variety of organisms. Such studies have, however, commonly been limited to some particular sampling scales. Some studies focus on very small scales and compare individual genotypes in order to obtain information about spatial clustering of 
relatives (e.g. Ishibashi et al., 1997a) or local groups of similar genotypes (e.g. van Staden et al., 1996). Other studies, addressing the consequences of habitat fragmentation, compare samples from habitat fragments of a certain size to samples taken from a continuous habitat on a similar scale (e.g. Knutsen et al., 2000). Few studies have attempted to compare levels of genetic differentiation at different geographical scales (e.g. Leblois et al., 2000). This we do here.

The Siberian lemming is a microtine rodent that is widespread on the tundra of the Russian Arctic, from the White Sea to north-eastern Siberia (e.g. Stenseth \& Ims, 1993: chap. 3). In largely undisturbed regions, such as the northern part of Taimyr Peninsula, the tundra is a relatively homogeneous environment; suitable habitat for Siberian lemmings is predominant in the lowlands of this area. As in most of the Siberian Arctic, the Siberian lemming is the most common small rodent species on northern Taimyr (Sdobnikov, 1957; Chernyavski \& Tkachev, 1982) and may be considered a good model of an abundant species living in a continuous habitat. Their numbers vary, however, with great amplitude as they experience large, regular fluctuations in population densities typical for northern microtine rodents (Sdobnikov, 1957; Stenseth \& Ims, 1993: chap. 4).

Only fragmentary information is available on the spatial biology of lemmings. Mass movements similar to those described for the Norwegian lemming (L. lemmus) in Fennoscandia have not been reported in Siberian lemmings (Stenseth \& Ims, 1993: chap. 8). For this species, local migratory movements during snow melt in spring seem typical. These movements rarely exceed one kilometre but may be quite conspicuous in years of high population densities (Chernyavski \& Tkachev, 1982). During spring, lemmings have been observed on snow and ice. They have also been reported to cross a one kilometre wide frozen river on the Taimyr Peninsula and to swim over $30 \mathrm{~m}$ of open water (Orlov, 1980). Male lemmings appear to move more than females (e.g. Stenseth \& Ims, 1993: chap. 20), as is typical for most microtine rodents (e.g. Gaines \& McClenaghan, 1980). Home ranges are larger for males with an average estimate of 1.3 ha vs. 0.7 ha for females in L. sibiricus (Chernyavski \& Tkachev, 1982) - estimates which are in the same order of magnitude as for other Lemmus species (Banks et al., 1975; C. Gower, personal communication). Sex-biased dispersal is expected to be reflected in the genetic data as contrasting female vs. male patterns (cf. Favre et al., 1997).

Here we aim to determine the scale at which genetic differentiation is evident in Siberian lemmings, and we ask in particular whether isolation by distance is found in the more or less continuous tundra habitat on western Taimyr. We analysed the spatial distribution of individ- ual genotypes, as well as discrete population samples separated by different geographical scales. Sex-specific patterns of genetic differentiation were also addressed. We found a 'patchy' genetic structure characterized by negligible local differentiation up to about $8 \mathrm{~km}$ or more, no pattern of isolation by distance among such patches and a tendency for related genotypes to be clustered at the smallest scale. We interpreted these patterns as populations not yet having reached an equilibrium structure after a major mixing event - an interpretation supported by the lack of concordance between mitochondrial DNA phylogeny and the geographical distribution of haplotypes. We furthermore concluded that considerable male-biased gene flow occurs in Siberian lemmings.

\section{Materials and methods}

\section{Study area and sample collection}

Western Taimyr was chosen for its extensive continuous tundra areas. The landscape along the coast in this region consists of gently rolling hills up to $50 \mathrm{~m}$ high, with elevation gradually increasing inland. Numerous rivers flow into the sea. Most of the study area lies within the southern part of the arctic tundra subzone, and the four southernmost localities belong to the typical tundra subzone (Chernov \& Matveyeva, 1997). The habitat remains wet throughout the summer in low-lying depressions, whereas on the hills it becomes drier; along rivers a meadow-like vegetation is found. Siberian lemmings prefer wet areas, where the vegetation is characterized by sedges, cotton grass and mosses (e.g. Chernyavski \& Tkachev, 1982). During the summer, from July to mid-September, lemmings inhabit wet slopes or areas where the micro-relief allows them to establish dry burrows and feed in the wet meadows. The distribution of winter nests and runways indicates that in winter they concentrate in the lowest parts of the landscape, where a thick snow cover accumulates (Sdobnikov, 1957; D.E., personal observations). Distances between potential summer and winter habitats are up to $100 \mathrm{~m}$.

Sampling was carried out at three geographical scales. (1) At the smallest scale, 223 lemmings were collected more or less continuously over a linear transect $11 \mathrm{~km}$ long (referred to as 'the transect'); the geographical coordinates for each individual were determined using GPS. (2) At an intermediate scale, lemming samples were collected at 12 mainland localities separated by 10-30 km along the coast (Fig. 1). Sampling was carried out in the summer of 1998 (a year of rather low lemming densities) and 1999 (a peak density year). In 1998, lemmings were caught with snap-traps set in runways or 


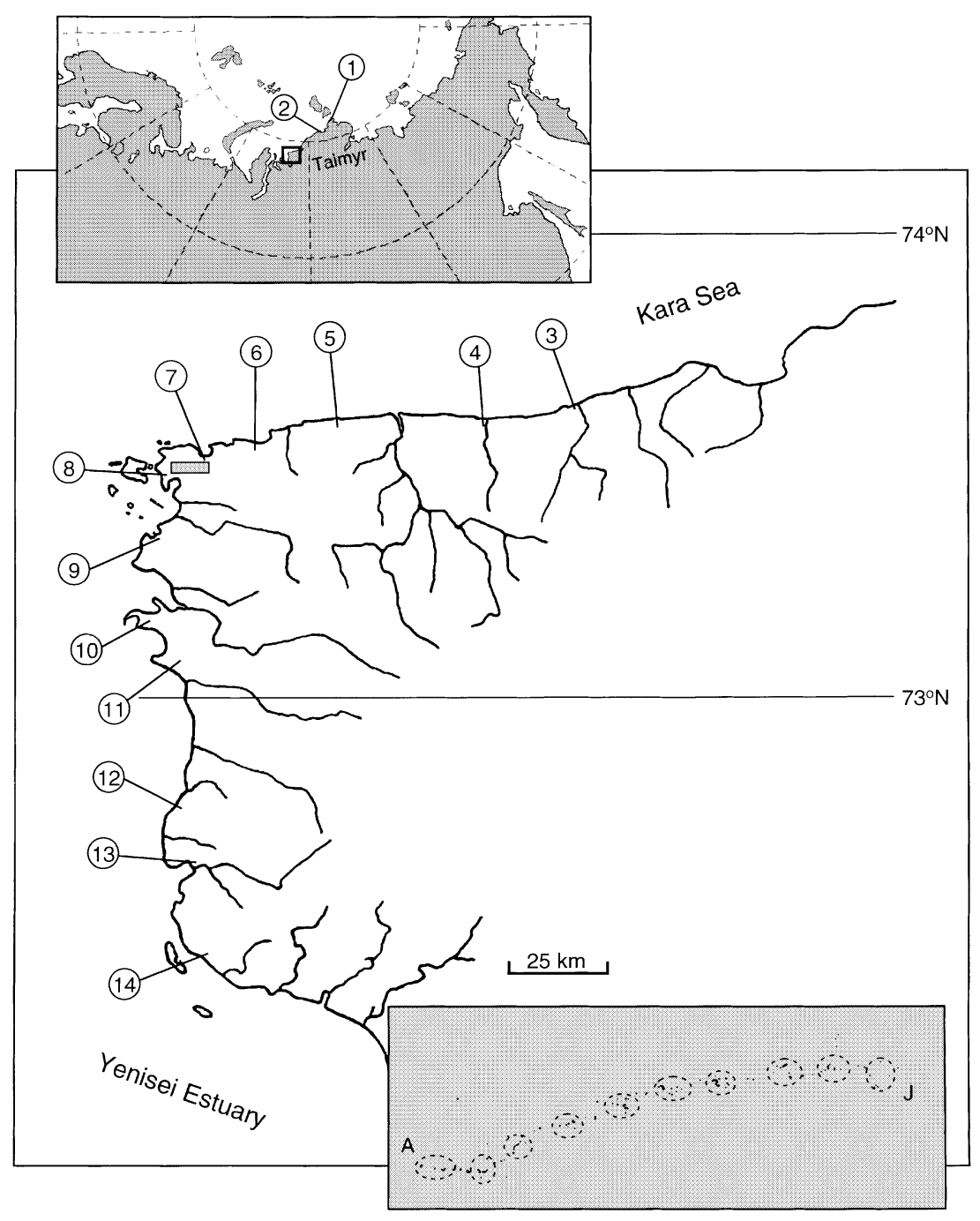

Fig. 1 Map of the study area. The small square in the upper insert indicates the geographical location of the main map. Locality names are as follows: (1) Cheliuskin, (2) northwestern Taimyr, (3) Morzhovaya, (4) Zeledeevo, (5) Dva Medvedya, (6) East Golomo, (7) West Golomo, (8) Dikson, (9) Medusa, (10) Budenovets, (11) Brazhnikova, (12) Osipovka, (13) Omulevaya and (14) Shirokaya. The shaded rectangle between localities 7 and 8 represents the small-scale transect: on the enlarged view (lower insert) dots represent individual lemmings and dotted circles indicate the 10 subsamples referred to as $\mathrm{A}$ to $\mathrm{J}$.

at the entrance of burrows. In 1999, most lemmings were captured or dug out of their burrows by a dog. In order to avoid sampling close relatives, we generally collected only one individual from each burrow system. (3) At the largest scale, specimens from two remote localities on northern Taimyr (1 and 2; Fig. 1) were obtained from the Swedish-Russian Tundra Ecology Expedition 1994 (Grönlund \& Melander, 1995).

The specimens collected were killed and liver, kidney or muscle tissue was preserved in $90 \%$ ethanol. Total genomic DNA was isolated using proteinase $\mathrm{K}$ digestion, $\mathrm{NaCl}$ precipitation of proteins and DNA precipitation with isopropanol (Miller et al., 1988).

\section{Genetic analysis}

Two types of genetic marker were used: the control region $(C R)$ of the mitochondrial genome (mtDNA), and four autosomal microsatellite loci. $m t D N A$. A 380-bp fragment of the $5^{\prime}$ hypervariable part of the mtDNA $C R$ was sequenced for a total of 346 Siberian lemmings. For PCR amplification we used primers designed from a Clethrionomys glareolus mtDNA sequence (GeneBank Accession no. Y07543): 5'-TCCCCCACCATCAGCACCC-3' and 5'-CATCCCGAAAATTAAAAAATACC-3'. Amplification was carried out in a total volume of $50 \mu \mathrm{L}$, which contained $0.5 \mu \mathrm{M}$ of each primer, a small amount of template DNA, $75 \mathrm{~mm}$ Tris- $\mathrm{HCl}(\mathrm{pH} 8.8), 20 \mathrm{~mm}\left(\mathrm{NH}_{4}\right)_{2} \mathrm{SO}_{4}$, $0.2 \mathrm{~mm}$ dNTP, $2.5 \mathrm{~mm} \mathrm{MgCl}_{2}$, and 0.5 units DyNAzyme II DNA polymerase (Finnzymes OY, Espoo, Finland). The PCR programme was $5 \mathrm{~min}$ at $94^{\circ} \mathrm{C}$, followed by 35 cycles of $30 \mathrm{~s}$ at $94^{\circ} \mathrm{C}, 30 \mathrm{~s}$ at $54^{\circ} \mathrm{C}$ and $1 \mathrm{~min}$ at $72^{\circ} \mathrm{C}$, then a final $5 \mathrm{~min}$ step at $72^{\circ} \mathrm{C}$. PCR fragments were purified using the PCR Product PreSequencing Kit (Amersham Life Sciences, Cleveland, $\mathrm{OH})$. Sequences were determined manually using the Thermo Sequenase Radiolabelled Terminator Cyclic 
Sequencing Kit (Amersham Life Sciences) and electrophoretic separation of the radioactively labelled fragments on polyacrylamide gels. Sequencing was also performed on an ABI Applied Biosystems 373A automated DNA sequencer using the Dye Terminator Cycle Sequencing Kit (PE Biosystems, Warrington, UK) according to the manufacturer's instructions. The primers used for sequencing were the same as used for PCR amplification. Sequences of $332 \mathrm{bp}$ (corresponding to positions 15 436-15 770 in Mus musculus; Bibb et al., 1981) were obtained for all individuals (GeneBank Accession Nos AF355404-AF355454, excluding AF355341 and AF355412).

Microsatellites. Initially, we tested 21 microsatellite primer pairs published for different species of microtine rodents. Four of them (MSCRB-5A, MSCRB-6, Ishibashi et al., 1997b; $A V-13$, Stewart et al., 1998; and MSCg-9, Gockel et al., 1997) detected polymorphic products and could be reliably scored (Table 1). The PCR amplification, for which one primer was endlabelled with radioactive $\alpha^{32} \mathrm{P}$-ATP, and electrophoresis of the fragments on polyacrylamide gels was carried out as described in Ehrich et al. (2001). Annealing temperatures and $\mathrm{MgCl}_{2}$ concentrations for each locus are given in Table 1.

\section{Statistical analysis}

For most analyses, we pooled samples from the intermediate (2) and the large-scale (3) localities. For the small-scale transect data, two types of analysis were used: an individual-based analysis (including 140 individual mtDNA $C R$ sequences and 204 genotypes at four microsatellite loci) and a group-based analysis for which the transect was divided a posteriori into 10 discrete geographical subsamples (A to $\mathrm{J}$ ) by excluding individuals from intermediate locations (Fig. 1).
Levels of mtDNA sequence polymorphism were estimated as unbiased haplotype diversity $(H)$ and nucleotide diversity using ARLEQUIN 1.1 software (Schneider et al., 1997). Levels of microsatellite polymorphism were estimated as average expected heterozygosity $\left(H_{\mathrm{E}}\right.$; Nei, 1987: p.178). Inbreeding coefficients $\left(F_{\text {IS }}\right)$ were calculated for each locality using the program FSTAT 2.8 (Goudet, 1995). GENEPOP 3.1 (Raymond \& Rousset, 1995) was used to conduct exact tests for deviations from Hardy-Weinberg and for linkage equilibrium for each locality and locus or pair of loci, respectively. For both series of exact tests the significance level was adjusted using a Bonferroni correction.

At the individual level, population structure was analysed using the mtDNA data by plotting the proportion of identical pairs of haplotypes per distance class. Spatial autocorrelation in the individual microsatellite data was examined by calculating Smouse \& Peakall's (1999) autocorrelation coefficient. In both cases, $300 \mathrm{~m}$ distance classes were chosen, corresponding roughly to twice an upper estimate of the diameter of Lemmus home ranges (Chernyavski \& Tkachev, 1982). Significant departures of spatial autocorrelation patterns from random distribution of genotypes was tested for by plotting the $95 \%$ null hypothesis confidence intervals. These confidence intervals were estimated by resampling, using 5000 permutations of individuals (four-locus genotypes for microsatellites) among geographical locations.

From the individual microsatellite data, we also estimated Wright's 'neighbourhood size' $4 D \pi \sigma^{2}$, where $D$ is the population density and $\sigma^{2}$ is the variance of the axial distance between parents and offspring under the assumption of isotropic dispersal in two dimensions. Because in this case the average distance is equal to zero $\sigma^{2}$ also corresponds to the average of the squared distances. The quantity $\sigma$ thus gives an indication about

Table 1 Species of origin and reference, repeat motif, PCR conditions (annealing temperature and $\mathrm{MgCl}_{2}$ concentration) and total number of identified alleles for the four microsatellite loci that were reliably amplified in Lemmus sibiricus. The repeat motif is given as described for the source species

\begin{tabular}{|c|c|c|c|c|c|}
\hline Locus & Source & Repeat motif & Annealing temp. & $\mathrm{MgCl}_{2}$ & Alleles \\
\hline$M S C R B-5 A$ & $\begin{array}{l}\text { Clethrionomys rufocanus } \\
\text { (Ishibashi et al., 1997b) }\end{array}$ & $\begin{array}{l}\text { Mixture of CA, } \\
\text { ATAC and ATGT }\end{array}$ & $54^{\circ} \mathrm{C}$ & $2.5 \mathrm{~mm}$ & 4 \\
\hline$M S C R B-6$ & (Ishibashi et al., 1997b) & Mixture of $\mathrm{AC}$ and $\mathrm{AG}$ & $55^{\circ} \mathrm{C}$ & $2.5 \mathrm{~mm}$ & 6 \\
\hline$A V-13$ & $\begin{array}{l}\text { Arvicola terrestris } \\
\text { (Stewart et al., 1998) }\end{array}$ & GATA & $52^{\circ} \mathrm{C}$ & $1.5 \mathrm{~mm}$ & 15 \\
\hline$M S C g-9$ & $\begin{array}{l}\text { Clethrionomys glareolus } \\
\text { (Gockel et al., 1997) }\end{array}$ & CA (interrupted) & $58^{\circ} \mathrm{C}$ & $1.5 \mathrm{~mm}$ & 33 \\
\hline
\end{tabular}

The following primer sets were tested but proved unusable: MSCRB-2, MSCRB-3, MSCRB-4 and MSCRB-7 (Clethrionomys rufocanus, Ishibashi et al., 1997b); MSCg-15, MSCg-19, MSCg-20 (C. glareolus, Gockel et al., 1997); MSMM-2, MSMM-3, MSMM-4, MSMM-6 (Microtus montbelli, Ishibashi et al., 1999); $A V-7, A V-9, A V-10, A V-12, A V-14, A V-15$ (Arvicola terrestris, Stewart et al., 1998).

(c) The Genetics Society of Great Britain, Heredity, 86, 716-730. 
the average gene flow distance per generation (Rousset, 1997). The neighbourhood size was estimated as the inverse of the slope of the regression line of $a_{r}$ (a parameter analogous to $F_{\mathrm{ST}} /\left(1-F_{\mathrm{ST}}\right)$ which can be estimated for pairs of individuals) vs. the logarithm of geographical distance (ln-distance) according to Rousset (2000). This approximate linear relationship is expected to hold less well at very short distances (less than $\sigma$ ) and to progressively depart from linearity at large distances, depending on the mutation rate $(\mu)$ of the genetic marker used. Distances recommended for estimation range from $\sigma$ to $0.5 \sigma / \sqrt{ } 2 \mu$ (Rousset, 1997). Assuming a mutation rate of $\mu=5 \times 10^{-4}$ for microsatellite loci (e.g. Goldstein \& Schlötterer, 1999) and arbitrarily choosing $\sigma=150 \mathrm{~m}$, the recommended upper limit is in the order of $2.5 \mathrm{~km}$, whereas for $\sigma=500 \mathrm{~m}$ it is around $8 \mathrm{~km}$. Because independent estimates of $\sigma$ are lacking for Siberian lemmings, we excluded comparisons between individuals separated by less than $150 \mathrm{~m}$ and estimated the regression slope for maximal distances ranging from $1 \mathrm{~km}$ to $11 \mathrm{~km}$ (total transect). The significance of the slopes was tested by a Mantel test (5000 permutations of individuals among geographical locations; Mantel, 1967).

The genetic population structure among discrete sampling localities (the 10 subsamples of the transect as well as the larger scales) was characterized from haplotype or allele frequencies by $F_{\mathrm{ST}}$-values estimated in an analysis of molecular variance (AMOVA) using ARLEQUIN 1.1. Our study focused on the effects of local genetic drift vs. migration in shaping population structure at a spatial and temporal scale at which the influence of mutation is assumed to be negligible. Therefore, sequence differences among mtDNA haplotypes or differences in number of repeats among microsatellite alleles were ignored. Private mtDNA haplotypes occurring within one local sample were pooled for the frequency analysis. Locality 5, where only four individuals were captured, was excluded from the Amova. Confidence intervals were estimated for microsatellite values as the second smallest and the second largest value of all 35 possible 'bootstrap' resampling arrangements across the four analysed loci. In addition, $F_{\mathrm{ST}}$ was calculated for pairs of adjacent localities. All $F_{\mathrm{ST}}$-estimates were tested for significant difference from zero by means of a permutation test exchanging individual genotypes between populations (using 10000 permutations or 1000 permutations for pairwise estimates). Isolation by distance was analysed by regressing pairwise estimates of $F_{\mathrm{ST}} /\left(1-F_{\mathrm{ST}}\right)$ against ln-distance between sites (Rousset, 1997). A Mantel test was performed to test the correlation between genetic differentiation and geographical distance using GENEPOP 3.1 (10 000 permutations).
The degree to which the observed microsatellite allele frequencies were characteristic of each sampling locality was examined by reassigning each individual to the sample where its genotype was most likely to occur (assignment test; Waser \& Strobeck, 1998). The calculations were carried out with the ASSIGNMENT CALCULATOR program (J. Brzustowski; available at http:// gause.biology.ualberta.ca/jbrzusto/Doh.html), choosing the option to adjust all allele frequencies in every population in order to avoid zero frequencies. Significant departure from a random distribution of genotypes was tested for by 10000 randomizations, which were created by resampling existing individuals with replacement from the combined pool of populations. A corrected assignment index $\left(A I_{\mathrm{c}}\right.$; cf. Favre et al., 1997) was calculated for each individual by subtracting population means after log-transforming the probability of occurrence of its genotype in its original locality. The $A I_{\mathrm{c}}$-values were compared between the sexes (excluding juveniles) to address sex-specific patterns (Favre et al., 1997).

A mtDNA $C R$ cladogram was constructed according to the phylogeny reconstruction algorithm described by Templeton et al. (1992) using the software TCs 1.0 (Clement et al., 2000). This method, which was specifically developed for intraspecific phylogeny, estimates a network with connections having a probability of more than 0.95 of being parsimonious. The maximum number of differences between sequences allowing parsimonious connections was estimated using the program PARSPROB 1.1 (D. Posada; available at http://bioag.byu.edu/ zoology/crandall_lab/programs.htm). When parsimony cannot be justified at the 0.95 probability level, both parsimonious and non-parsimonious connections are allowed until the cumulative probability of the connections exceeds 0.95 (Templeton et al., 1992). The algorithm thus explicitly allows for ambiguities in the cladogram.

\section{Results}

\section{Gene diversity}

The mtDNA $C R$ sequences were highly variable. A total of 49 different haplotypes was found among the 346 individuals analysed (see Appendix 1). At the two larger geographical scales, the average sample size $(n)$ per locality was 16 individuals (ranging from 8 to 24 , excluding locality 5) and haplotype diversity ranged from 0.55 to 0.91 (average $H=0.82, \mathrm{SD}=0.11$ ). Among the 140 individuals of the transect, 20 different haplotypes were found and haplotype diversity ranged from 0.69 to 0.92 (average $H=0.86, \mathrm{SD}=0.07$ ) in the 10 subsamples (average $n=10$, ranging from 8 to 12). 
Thirty-nine nucleotide positions were variable in the analysed fragment (Appendix 2). The haplotypes differed by up to $17 \mathrm{bp}(5.15 \%)$ and the mean number of pairwise differences was 7.7 ( $\mathrm{SD}=3.6)$, resulting in an overall nucleotide diversity of $2.33 \% \quad(\mathrm{SD}=1.20 \%)$. Nucleotide diversity per locality ranged from $0.87 \%$ to $2.60 \%$ at the larger scales, with an average of $1.99 \%$ $(\mathrm{SD}=0.45 \%)$. It was slightly higher for the 10 subsamples of the transect for which the average was $2.31 \%$ $(\mathrm{SD}=0.43 \%$, ranging from $1.76 \%$ to $2.75 \%)$. No geographical pattern in mtDNA diversity was evident. There was, however, considerable heterogeneity in the geographical distribution of the haplotypes (Appendix 1). Some haplotypes were common and occurred in almost all localities (e.g. haplotype 10), whereas others had a more limited geographical distribution. Apparently private haplotypes were found in most localities. Among these, 10 haplotypes were observed exclusively in one of the two remote northern localities, six at Cheliuskin (1) and four at north-western Taimyr (2).

Although the four microsatellite loci were polymorphic in all local samples, genetic variability differed considerably among loci. The number of alleles per locus ranged from four (with one highly frequent allele in all local populations) up to 33 (Table 1) and between two and 17 alleles were observed in samples from a single locality. Genetic diversity $\left(H_{\mathrm{E}}\right)$ differed considerably among loci. Average values were similar for localities at the different scales with average $H_{\mathrm{E}}=0.65$ $(\mathrm{SD}=0.04$, ranging from 0.57 to 0.71 ) for localities of the two larger geographical scales (average $n=19$, ranging from 8 to 29) and average $H_{\mathrm{E}}=0.67(\mathrm{SD}=0.04$, ranging from 0.61 to 0.74 ) for the subsamples of the transect (average $n=18$, ranging from 11 to 21). No consistent geographical pattern in microsatellite diversity was observed.

A significant deviation from Hardy-Weinberg proportions was observed only for locus $A V-13$ at northwestern Taimyr (2). There was, however, a tendency for a deficit of heterozygotes at all loci and scales, and estimated inbreeding coefficients $\left(F_{\text {IS }}\right)$ were positive for all local samples except Zeledeevo (4). This tendency was significant at the two larger sampling scales (sign test among all single locus $F_{\mathrm{IS}^{-}}$-values corresponding to a significant deviation from Hardy-Weinberg proportions at $\alpha=0.05: P=0.003)$. Because the observed heterozygote deficiency was not particular to one locus, it cannot be attributed to a null allele. The most likely explanation seems subdivision in some of the local populations (i.e. a Wahlund effect). No significant linkage disequilibrium occurred at any locality, nor was it detected between any pair of loci for the total transect data $(n=204)$. Hence, independence among loci was assumed in the further analyses.

(c) The Genetics Society of Great Britain, Heredity, 86, 716-730.

\section{Transect: individual-based analysis}

For the mtDNA data, a plot of the proportion of identical haplotypes per $300 \mathrm{~m}$ distance class showed a clear trend with distance. In particular, we observed a higher similarity than expected under random distribution among individuals in the first three classes, and significantly lower similarity in some classes beyond $8 \mathrm{~km}$ (Fig. 2a). For the microsatellite data on the other hand, no obvious pattern was apparent from the multilocus spatial autocorrelogram (Fig. 2b). There was, however, a slight tendency for a decrease in similarity with distance up to about $2.5 \mathrm{~km}$, with a single significantly positive autocorrelation coefficient in the second distance class $(300-600 \mathrm{~m}$ between

(a) mtDNA CR

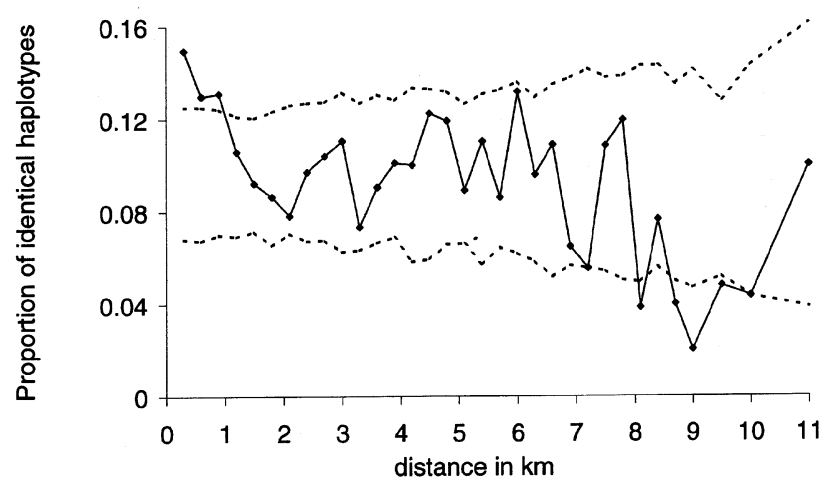

(b) Microsatellites

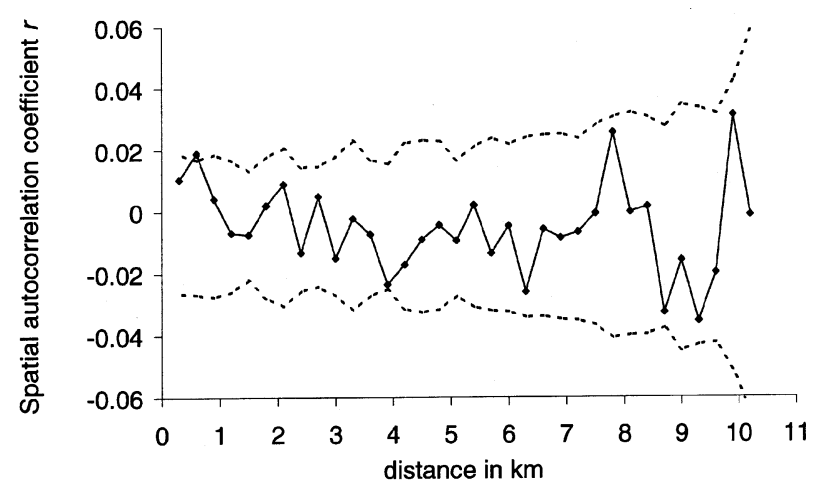

Fig. 2 Genetic similarity between individual Siberian lemmings on the $11 \mathrm{~km}$ transect vs. geographical distance. A $95 \%$ null hypothesis confidence interval was estimated from 5000 permutations of individuals among geographical locations and is indicated by dotted lines. (a) Proportion of identical pairs of mtDNA $C R$ haplotypes per $300 \mathrm{~m}$ distance class. (b) Spatial autocorrelogram estimated from multilocus microsatellite genotypes for $300 \mathrm{~m}$ distance classes. 
individuals). The same statistics were plotted for each sex separately (not shown). For both genetic markers, a marginally significant tendency for higher similarity at short distances (below $1 \mathrm{~km}$ for mtDNA and below $3 \mathrm{~km}$ for microsatellites) was apparent for females but not for males.

For all pairs of individuals separated by more than $150 \mathrm{~m}$, the slope of the regression of individual genetic differentiation $\left(a_{\mathrm{r}}\right.$; microsatellite data) against ln-distance was close to zero (estimated slope: 0.0003). The slope was, however, significantly positive when only parts of the transect were included in the analysis and pairs of individuals separated by the largest distances (more than $7.5 \mathrm{~km}$ ) were excluded (Fig. 3). Estimates of the slope for this part were between 0.004 and 0.01 , corresponding to neighbourhood sizes between 250 and 100 .

\section{Transect: subsample analysis}

The mtDNA sequences showed moderate, but significant, differentiation among the 10 subsamples of the transect with an $F_{\mathrm{ST}}$ of 0.058 (Table 2). Pairwise $F_{\mathrm{ST}}$-values between neighbouring subsamples revealed that this differentiation was mainly due to an abrupt differentiation between subsamples $\mathrm{H}$ and I (Table 3). Dividing the transect at this position resulted in nonsignificant differentiation on each side of this 'border' (A-H: $F_{\mathrm{ST}}=0.025, P=0.09 ; \mathrm{I}-\mathrm{J}: F_{\mathrm{ST}}=0.061, P=0.11$ ). In order to examine the extent of the observed areas of no differentiation, we included the surrounding sampling localities in the analysis. Dikson (8) was negligibly differentiated from A-H $\left(F_{\mathrm{ST}}=0.026, P=0.07\right)$. West Golomo (7) was less differentiated from A-H $\left(F_{\mathrm{ST}}=0.027, \quad P=0.07\right)$ than from $\mathrm{I}-\mathrm{J} \quad\left(F_{\mathrm{ST}}=0.1\right.$, $P=0.01$ ), and East Golomo (6) was not differentiated from $\mathrm{I}-\mathrm{J}\left(F_{\mathrm{ST}}=0.021, P=0.23\right)$. The pattern emerging from these observations is that there are two distinct patches, within which mtDNA haplotype frequencies show no differentiation.

For the microsatellite data differentiation was lower than for mtDNA with an $F_{\mathrm{ST}}$ of 0.014 (but still significantly greater than zero; Table 2). Pairwise $F_{\mathrm{ST}}$-values between neighbouring subsamples showed that most differentiation was found around subsample B (Table 3). Differentiation among the subsamples C-J was not significant $\left(F_{\mathrm{ST}}=0.007, P=0.08\right)$. As above, surrounding sampling localities were included in the AMova: $\mathrm{C}-\mathrm{J}$ were not differentiated from West and East Golomo (6 and 7; $F_{\mathrm{ST}}=0.008, P=0.07$ ) and $\mathrm{B}$ was not

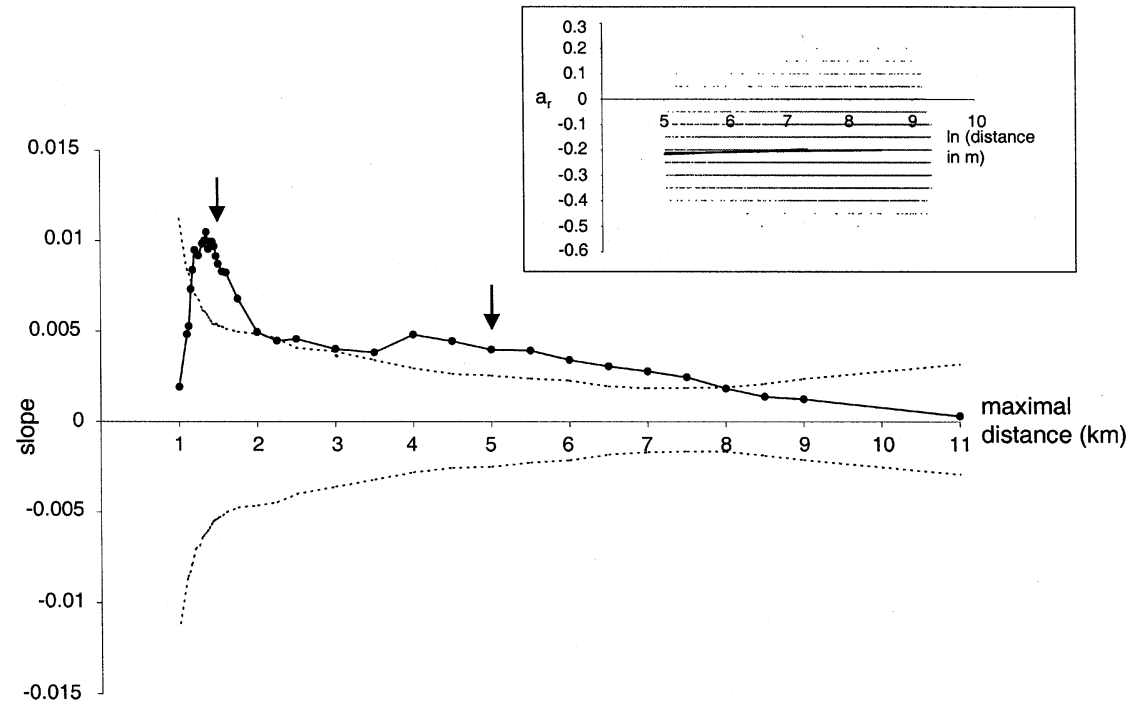

\begin{tabular}{lccrrrr}
\hline & \multicolumn{2}{c}{ mtDNA $C R$} & & \multicolumn{3}{c}{ Microsatellites } \\
\cline { 2 - 3 } \cline { 5 - 7 } & $F_{\mathrm{ST}}$ & \multicolumn{1}{c}{$P$} & & $F_{\mathrm{ST}}$ & $P$ & $\mathrm{CI}$ \\
\hline Transect & 0.058 & 0.0017 & & 0.014 & 0.0038 & $0.008-0.019$ \\
$\begin{array}{l}\text { Intermediate scale } \\
\text { Intermediate and }\end{array}$ & 0.18 & $<0.0001$ & & 0.026 & $<0.0001$ & $0.017-0.039$ \\
large scale & 0.213 & $<0.0001$ & & 0.03 & $<0.0001$ & $0.015-0.043$ \\
\hline
\end{tabular}

Fig. 3 Genetic differentiation at four microsatellite loci between individual Siberian lemmings on the $11 \mathrm{~km}$ transect. The insert shows pairwise estimates of $a_{\mathrm{r}}$ plotted against ln-distance, as well as two examples of regression lines including pairs of individuals separated by distances up to $1.5 \mathrm{~km}$ and $5 \mathrm{~km}$. On the main figure the slopes of such regressions are plotted against the maximal distance taken into account for the estimation. The arrows indicate the location of the two example lines from the insert. Null hypothesis $95 \%$ confidence intervals were estimated from 5000 permutations of individuals among geographical locations and are indicated by dotted lines.

Table 2 Genetic differentiation among local samples of Siberian lemmings at different geographical scales 
Table 3 Pairwise $F_{\mathrm{ST}}$-estimates among neighbouring subsamples of Siberian lemmings on the small-scale transect

\begin{tabular}{lcc}
\hline & mtDNA control region & Microsatellites (four loci) \\
\hline A & -0.003 & $0.069^{* *}$ \\
B & 0.001 & $0.043^{* *}$ \\
C & 0.044 & 0.006 \\
D & 0.01 & 0.016 \\
E & -0.013 & -0.001 \\
F & 0.004 & 0.012 \\
G & 0.067 & 0.003 \\
H & $0.204^{* *}$ & -0.02 \\
I & 0.061 & -0.002 \\
J & & \\
\hline
\end{tabular}

$* * P<0.01$.

differentiated from Dikson $\left(8 ; F_{\mathrm{ST}}=0.015, P=0.12\right)$, indicating areas with homogeneous distributions of allele frequencies comparable to those revealed by the mtDNA data. In agreement with the $F$-statistics, an assignment test showed weak genetic structuring of microsatellites at this scale: only $14 \%$ of the individuals were correctly assigned to their source sample and only subsample B was significantly characterized by the observed allele frequencies $(P=0.035)$. Mean $A I_{\mathrm{c}}$-estimates were slightly lower for males than for females (mean $A I_{\mathrm{c}}=-0.059$ for males and 0.048 for females), but the difference between sexes was not significant (Mann-Whitney $U$-test).

Pairwise estimates of $F_{\mathrm{ST}} /\left(1-F_{\mathrm{ST}}\right)$ from the mtDNA data increased significantly with ln-distance (Fig. 4; Mantel test $P=0.042$ ). This positive correlation was, however, largely due to the fact that samples from opposite sides of the 'border' were, on average, both genetically more differentiated and geographically more distant, and thus cannot readily be interpreted as a progressive pattern of increased differentiation with distance on this scale. No correlation of genetic differentiation with geographical distance was observed for the microsatellite data (Fig. 4).

\section{Intermediate and large scale}

Both markers showed clear genetic differentiation among localities at the intermediate sampling scale. For the mtDNA data, the $F_{\mathrm{ST}}$-estimate of 0.18 was considerably higher than within the transect (Table 2). Only a slight additional increase in $F_{\mathrm{ST}}$ was observed for both markers when including the two remote northern sites (cf. Table 2). For mtDNA, pairwise $F_{\mathrm{ST}}$-estimates revealed significant differentiation between all neighbouring localities (Table 4). For microsatellites, differentiation was weaker and significant only for four pairs of neighbouring localities (Table 4). In fact, when excluding localities 7-10 from the AMOVA, differentiation among the remaining localities of the intermediate sampling scale was not significant $\left(F_{\mathrm{ST}}=0.009\right.$, $P=0.08)$.

The assignment test for microsatellites revealed a somewhat clearer characterization of local samples at
Fig. 4 Genetic differentiation with distance for mtDNA and microsatellite data among pairs of subsamples of the transect (small scale) and pairs of localities (intermediate and large scale): pairwise estimates of $F_{\mathrm{ST}} /\left(1-F_{\mathrm{ST}}\right)$ are plotted against ln-distance. In the first panel, the fitted regression is

$F_{\mathrm{ST}} /\left(1-F_{\mathrm{ST}}\right)=-0.11+0.02 \ln ($ distance); full circles represent pairs of subsamples within one genetic patch, whereas open circles represent pairs from different patches.

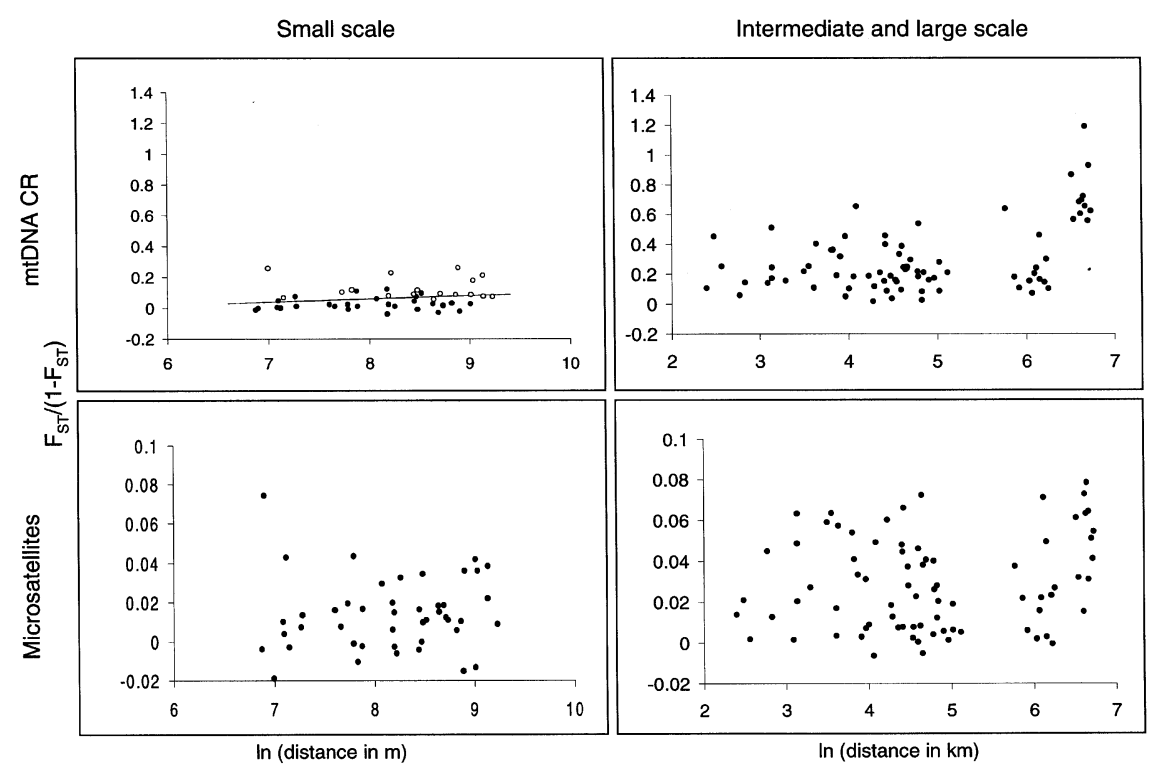


Table 4 Pairwise $F_{\mathrm{ST}}$-estimates among neighbouring samples of Siberian lemmings at an intermediate and large scale. The dotted lines represent the larger geographical distances to the first two localities (cf. Fig. 1)

\begin{tabular}{|c|c|c|}
\hline & $\begin{array}{c}\text { mtDNA } \\
\text { control region }\end{array}$ & $\begin{array}{c}\text { Microsatellites } \\
\text { (four loci) }\end{array}$ \\
\hline \multicolumn{3}{|l|}{ 1. Cheliuskin } \\
\hline & $0.388 * *$ & $0.042 * *$ \\
\hline \multicolumn{3}{|l|}{ 2. NW Taimyr } \\
\hline & $0.15^{*}$ & 0.032 \\
\hline \multicolumn{3}{|l|}{ 3. Morzhovaya } \\
\hline \multicolumn{3}{|l|}{ 4. Zeledeevo } \\
\hline & $0.092 * *$ & 0.007 \\
\hline \multicolumn{3}{|l|}{ 6. E. Golomo } \\
\hline & $0.123 * *$ & 0.015 \\
\hline \multicolumn{3}{|l|}{ 7. W. Golomo } \\
\hline \multicolumn{3}{|l|}{ 8. Dikson } \\
\hline & $0.053^{*}$ & $0.041 * *$ \\
\hline \multicolumn{2}{|l|}{ 9. Medusa } & $0.056 * *$ \\
\hline \multicolumn{3}{|l|}{ 10. Budenovets } \\
\hline 11. Brazhnikova & $0.093 * *$ & 0.007 \\
\hline 12. Osipovka & $0.201 * *$ & 0.005 \\
\hline 13. Omulevaya & $0.194 * *$ & 0.022 \\
\hline 14. Shirokaya & & \\
\hline
\end{tabular}

$* P<0.05 ; * * P<0.01$.

the intermediate sampling scale. Among all individuals, $34 \%$ were correctly assigned to their source locality, and the number of correctly assigned individuals was significantly higher than under random distribution of genotypes for eight of the 11 sampling localities. Characterization of the local samples was weaker in the southern part of the study area and not significant for Brazhnikova (11), Omulevaya (13) and Shirokaya (14). As indicated at the small scale, $A I_{\mathrm{c}}$-estimates at the intermediate scale were significantly more negative for males than for females (mean $A I_{\mathrm{c}}=-0.023$ for males and 0.028 for females; Mann-Whitney $U$-test: $0.01<$ $P<0.02)$.

No pattern of increased genetic differentiation with geographical distance was observed for either genetic marker at the intermediate scale (Fig. 4). Pairwise estimates of $F_{\mathrm{ST}} /\left(1-F_{\mathrm{ST}}\right)$ were somewhat higher only when including the northernmost locality, Cheliuskin (1). For microsatellites, the lack of concordance between genetic similarity and geography was confirmed by an UPGMA cluster diagram (not shown) based on Nei's unbiased genetic distance among localities (Nei, 1987), which showed no clear clustering of adjacent localities (mtDNA see below). Pairwise values of $F_{\mathrm{ST}} /\left(1-F_{\mathrm{ST}}\right)$ were, however, generally higher at the intermediate scale than at the small scale of the transect (Fig. 4).

\section{mtDNA CR phylogeography}

A cladogram allowed us to identify distinct groups of related mtDNA haplotypes, despite a considerable amount of homoplasy in the dataset reflected by several unresolved loops (Fig. 5). Seven-bp differences were estimated as the maximum for parsimonious connections at a 0.95 probability level. Group B, whose haplotypes differ from all the others by at least $9 \mathrm{bp}$, could therefore not be connected in a parsimonious way to the rest of the network. In addition to the cladogram, a neighbour-joining (NJ) tree based on Kimura's twoparameter distance among haplotypes (not shown) was estimated using the program MEGA 1.0 (Kumar et al., 1993). The clades of the NJ tree correspond to the groups appearing in the cladogram. Statistical support of the clades was assessed by 5000 bootstrap replicates of the NJ tree. Two of the larger haplotype groups correspond to clades with noteworthy bootstrap support. Hence, three major lineages could be identified: A (66\% bootstrap support), B ( $90 \%$ bootstrap support), and the remaining haplotypes.

No associations of the three major lineages or other clades could be observed with geographical locations. Thus, haplotypes specific to the two remote northern localities (1 and 2) were spread over most of the cladogram and occurred in all phylogenetic groups, except in the clade surrounding haplotype 7 (Fig. 5). All three major lineages were geographically widespread on the scale of our study and closely related haplotypes were often found in distant localities (Appendix 1).

\section{Discussion}

\section{Patchy genetic structure}

The genetic structure of the Siberian lemming populations was characterized by patches of genetic similarity, among which no larger scale pattern was obvious. There was, notably, no progressive increase in differentiation with geographical distance as expected under the isolation-by-distance model. This general pattern was particularly clear for mtDNA. In the transect, most of the genetic differentiation could be attributed to a division into two distinct groups of subsamples, within which haplotype distribution was relatively homogeneous. Localities 7 and 8, sampled in 1998 adjacent to the transect, which was sampled in 1999, could be attributed 
Fig. 5 Network showing the relationships among the 49 mtDNA $C R$ haplotypes observed in Siberian lemmings. Numbers in circles identify the haplotypes and sizes of the circles are proportional to the number of individuals with each haplotype. Dark shading indicates haplotypes found only at Cheliuskin (1) and light shading indicates haplotypes found only at north-western Taimyr (2). Dotted lines surround clades supported by more than $65 \%$ (thin) or $90 \%$ (bold) bootstrap support in a neighbour-joining tree showing the same structure as the present network. A and B designate two of the three major lineages which could be identified; the rest of the network was considered as the third.

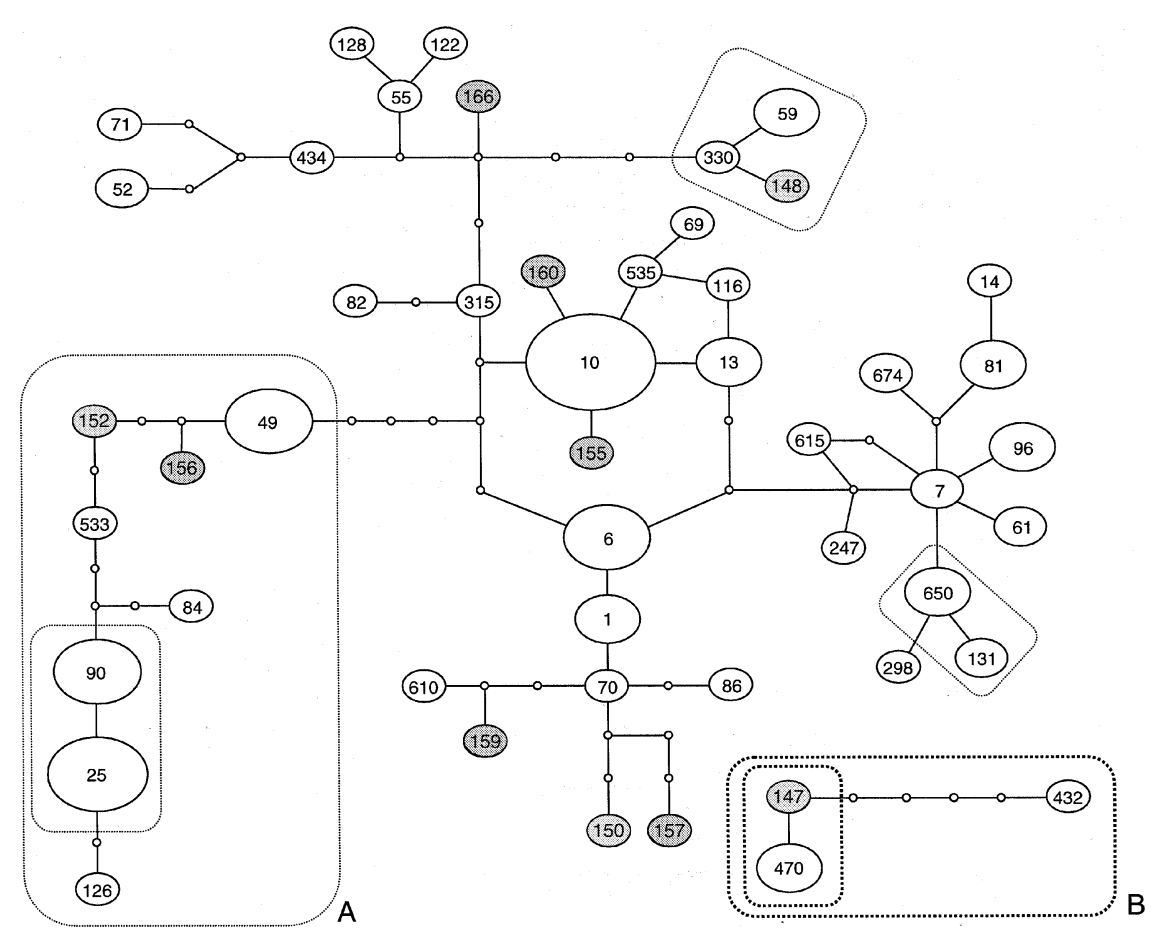

to either patch, showing that the pattern was stable over at least two years. Despite the abrupt genetic division into two groups, we could not identify any corresponding physical barrier to movement in the field (such as a large river or a cliff), which could explain the genetic division between subsamples $\mathrm{H}$ and $\mathrm{I}$. The first genetic patch (including subsamples $\mathrm{A}-\mathrm{H}$ ) covered at least $8 \mathrm{~km}$, whereas the second might extend over as much as $17 \mathrm{~km}$, as subsamples $\mathrm{I}$ and $\mathrm{J}$ were not significantly differentiated from the more remote East Golomo (6). On the intermediate scale, where distances between sampling localities were in the order of magnitude of the identified patches or larger, genetic differentiation was clear among all neighbouring samples, but did not increase with geographical distance. An increase in genetic differentiation was observed only at the large scale for pairs of localities including Cheliuskin (1; the northernmost locality).

The pattern revealed by microsatellites was largely consistent with the patchy structure of mtDNA variation. In the transect, the distribution of genetic variability might be interpreted as two patches of relative homogeneity comparable to those described for mtDNA, but the border between them occurred at a different location. This microgeographic discrepancy, together with the absence of visible geographical barriers at either genetic border, suggests that the observed pattern might be created by gene flow in the absence of habitat constraints. Because the mtDNA data reflect only female gene flow (and male dispersal within generations) whereas the autosomal microsatellite data reflect gene flow by both sexes, we might expect structures resulting from local gene flow and genetic drift to be different for the two types of markers, if gene flow is sex biased (see below). As for mtDNA, no pattern of progressive increase of microsatellite differentiation with geographical distance was observed at any scale.

The lower genetic differentiation ( $F_{\mathrm{ST}_{\mathrm{T}} \text {-estimates) }}$ revealed by the microsatellite data as compared to mtDNA at all scales may be explained by the four times higher effective number of genes at the diploid autosomal loci than for the haploid mtDNA. As differentiation due to genetic drift is proportional to the effective number of genes, assuming equal sex ratios, an approximately four times lower $F_{\mathrm{ST}}$ may be expected (Birky et al., 1983). In addition, $F_{\mathrm{ST}}$-estimates are affected by gene diversity, which in turn is determined by the mutation rate and the effective population size (Hedrick, 1999). The surprising lack of genetic differentiation among the eastern and the southern localities of the intermediate sampling scale thus cannot readily be attributed to long-distance gene flow, but is as likely due to high mutation rates in relatively large populations. The measurable effect of genetic drift may be additionally reduced for microsatellite loci, as mutations at these loci (e.g. Goldstein \& Schlötterer, 1999) may often not create distinguishable new alleles, but alleles identical to those present or having been present in the population. 


\section{Isolation by distance}

The absence of an increase of genetic differentiation with distance might be explained, also at larger scales, by gene flow and random long-range dispersal of individual lemmings. This would imply assuming an island model (Wright, 1943) with a certain, quite low, number of migrants equally likely to be exchanged among adjacent and more distant localities. At the intermediate geographical scale of the present study, the number of animals migrating over distances from 10 to $170 \mathrm{~km}$ would have to be considered equal. We consider such a scenario highly unlikely. Siberian lemmings have in fact been reported to move typically over distances below one km (Orlov, 1980; Chernyavski \& Tkachev, 1982) and in the present study we infer considerable gene flow at a local scale of hundreds of metres to a few $\mathrm{km}$ (see below).

Alternatively, the absence of an observable pattern of isolation by distance may suggest that a species has recently colonized the region (Slatkin, 1993). After the initial establishment of a population devoid of structure, local genetic drift should first result in a detectable increase of genetic differentiation with distance in the short distance range. This pattern will be weaker for more ongoing gene flow and will only slowly extend to larger geographical areas (Slatkin, 1993; P. E. Jorde, unpublished). The patchy genetic structure we observed in Siberian lemmings may thus be interpreted as a system not yet having reached drift-migration equilibrium after the establishment of the populations in the region or after a major mixing event. Whereas gene frequencies in our local samples did not show any pattern of isolation by distance, the analysis of individual genotypes revealed a slight tendency for decreasing genetic similarity with distance. In addition to considerable gene flow, immigration from adjacent areas, random long-distance dispersal (notably of males, see below) or high mutation rates (in the case of microsatellites) might explain the weakness of spatial autocorrelation at the small scale of the transect (Hardy \& Vekemans, 1999).

Interpreting the observed genetic structure as resulting from recently established populations, is supported by the phylogeographic analysis of the mtDNA haplotypes. The lack of concordance between the phylogeny and the geographical distribution of haplotypes does indeed indicate that the high observed mtDNA diversity did not arise in situ, but was present before the populations were established, or before some possible major mixing event. Fedorov et al. (1999) studied the phylogeography of Lemmus over the entire Eurasian Arctic and found no clear relatedness among geographically co-distributed mtDNA haplotypes (RFLP data) within considerable regions of the major phylogenetic groups. Notably among three localities on the Taimyr Peninsula (our localities 1 and 2 and a sample from north-eastern Taimyr), pairs of haplotypes from the same population had no less divergent sequences than pairs from different populations. Fedorov et al. (1999) suggest that the observed lack of population structure in mtDNA within regions resulted from distribution shifts of populations with high ancestral haplotype diversity during the Holocene, a hypothesis which is consistent with the interpretation of our data as resulting from a recent establishment or large-scale mixing of populations. It is worth noticing Sdobnikov (1957) who wrote that the arctic explorer Middendorf in 1843 (a peak lemming year) observed Siberian lemmings only as far north as $74^{\circ} \mathrm{N}$ on the Taimyr Peninsula (cf. Fig. 1), whereas nowadays they are distributed over the entire Peninsula. A general northward expansion of the distribution in such recent times might have resulted in a major mixing event, after which isolation by distance may slowly build up a genetic structure, creating the observed patchy structure.

\section{Neighbourhood size}

The regressions of $a_{\mathrm{r}}$ vs. In-distance allowed us to estimate $4 D \pi \sigma^{2}$ as the inverse of the regression slope. Although the detailed interpretation of Wright's neighbourhood concept is controversial, it has been suggested that this composite parameter may provide valuable information about population ecology (Rousset, 1997; 2000). We therefore attempt to interpret our genetic estimates of the neighbourhood size for Siberian lemmings, which were between 100 and 250 for significantly positive slopes, in terms of $\sigma$ and population density.

No estimates of the absolute population density of Siberian lemmings are available from the study area, and little is known about natal dispersal distances in this species. The effective population density, however, is clearly quite low, as the average effective size in populations periodically fluctuating in numbers is close to the size during the low-density phase (e.g. Motro \& Thomson, 1982). Lemmings (Lemmus sp.) are indeed well known for their particularly low numbers in some years (e.g. Boonstra et al., 1998). In addition, the genetically effective size of a population is typically smaller than the actual number of individuals (e.g. Frankham, 1995). Low-phase Siberian lemming densities have been estimated to be between 0 and 50 individuals per ha in the arctic tundra of north-eastern Taimyr (Underhill et al., 1993), and one individual or less per ha on Wrangel Island (Chernyavski \& Tkachev, 1982). Low effective density estimates would correspond to quite large gene flow per generation: An average 
effective population density of one lemming per ha would for example result in $\sigma$ between 300 and $450 \mathrm{~m}$. Considerable gene flow could in turn explain the observed lack of local genetic differentiation within patches extending over up to $8 \mathrm{~km}$ or more, and the weakness of spatial autocorrelation for individual genotypes on the small-scale transect.

\section{Male-biased dispersal}

Males had significantly more negative $A I_{\mathrm{c}}$ values than females at the intermediate scale; the same tendency, although not significant, was observed for the 10 subsamples of the transect. This result from the microsatellite analysis constitutes indirect evidence for malebiased dispersal (Favre et al., 1997), and is consistent with the general opinion that in lemmings males are the sex which moves more (e.g. Banks et al., 1975). A difference between sexes was observed also in the analysis of individual genotypes: for both markers, a trend for higher similarity among individuals up to one or a few $\mathrm{km}$ was apparent only for females. The relatively large average gene flow per generation deduced above, is thus likely to represent mostly male dispersal. At the larger geographical scales, male-biased dispersal may also be a factor contributing to the somewhat larger than expected difference observed between $F_{\mathrm{ST}}$-estimates from mtDNA haplotypes, reflecting only the female population structure, and microsatellite estimates, reflecting the whole population.

\section{Conclusions}

We have documented in this study a patchy genetic structure within continuously distributed populations of Siberian lemmings, with little genetic differentiation in areas extending over $8 \mathrm{~km}$ or more. Locally, the described structure allowed us to infer a considerable amount of gene flow resulting mostly from male dispersal. A tendency for local spatial autocorrelation among individual genotypes was apparent for females, which seem more sedentary. There was no larger-scale pattern of isolation by distance among patches. These findings disagree considerably with the expectations of the isolation-by-distance model and thus point to particularities of these lemming populations. The weakness of spatial autocorrelation at the small scale may be due to considerable gene flow. At the larger scales, however, the observed pattern is unlikely to result from random long-distance dispersal. It may rather be explained by the recent history of Siberian lemmings on the Taimyr. The interpretation of our observations as a system not yet having reached a migration-drift equilibrium structure provides insight into how contem- porary ecological processes like dispersal interact with population history to shape the extant geographical pattern of genetic variation.

\section{Acknowledgements}

We wish to thank V. Belov, K. Kleo, A. Belyashov, V. Krylov, K. Sal'nikov, A. Mingazhov, V. Gapaniuk and T. Akhlomova for help in the field, and L. Chuprov and the Great Arctic Nature Reserve for administrative support and permission to work on their territory. V. Fedorov kindly provided the samples from the Swedish-Russian Tundra Ecology Expedition '94. The genetic analysis was carried out at the DNA Laboratory for Molecular Ecology and Evolution of the University of Oslo and supported by grants from the University of Oslo and from the Norwegian Research Council (NFR). DE was funded by the Norwegian Research Council. We are grateful to E. Karlsen and V. Belov for help in the laboratory and to P. E. Jorde for valuable discussions and comments on the manuscript. We also want to thank J. Brzustowski and D. Posada for helping DE to use their programs and F. Rousset for statistical advice.

\section{References}

AVISE, J. C. 1994. Molecular Markers, Natural History and Evolution. Chapman \& Hall, New York.

BANKS, E. M., BROOKS, R. J. AND SCHNELL, J. 1975. A radiotracking study of home range and activity of the brown lemming (Lemmus trimucronatus). J. Mamm., 56, 888-901.

BIBB, M. J., VAN ETTEN, R. A., WRIGHT, C. T., WALBERG, M. W. ET AL. 1981. Sequence and gene organisation of mouse mitochondrial DNA. Cell, 26, 167-180.

BIRKY, C. W., MARUYAMA, T. AND FUERST, P. 1983. An approach to population and evolutionary genetic theory for genes in mitochondria and chloroplasts, and some results. Genetics, 103, 513-527.

BOONSTRA, R., KREBS, C. J. AND STENSETH, N. C. 1998. Population cycles in small mammals: The problem of explaining the low phase. Ecology, 79, 1479-1488.

CHERnOV, Y. I. AND MATVEYEVA, N. V. 1997. Arctic Ecosystems in Russia. In: Wielgolaski, F. E. (ed.) Polar and Alpine Tundra, Ecosystems of the World, 3rd edn, pp. 361-507. Elsevier Science, Amsterdam.

Chernyavski, F. B. AND TKACHev, A. v. 1982. Population Cycles of Arctic Lemmings. Ecological and Endocrinological Aspects. Nauka, Moskva (in Russian).

CLEMENT, M., POSADA, D. AND CRANDALl, K. 2000. TCS: $a$ computer program to estimate gene genealogies. Mol. Ecol., 9, 1657-1659.

EHRICH, D., JORDE, P. E., KREBS, C. J., KENNEY, A. K. ET AL. 2001, in press. Spatial structure of lemming populations (Dicrostonyx groenlandicus) fluctuating in density. Mol. Ecol., 10, 481-495. 
FAVRe, L., BALlouX, F., GOUdet, J. AND PERrin, N. 1997. Female-biased dispersal in the monogamous mammal Crocidura russula. Evidence from field data and microsatellite patterns. Proc. R. Soc. B, 264, 127-132.

FEDOROV, v., GOROPASHNAYA, A., JARRELL, G. H. AND FREDGA, K. 1999. Phylogeographic structure and mitochondrial DNA variation in true lemmings (Lemmus) from the Eurasian Arctic. Biol. J. Linn. Soc., 66, 357-371.

FRANKHAM, R. 1995. Effective population-size adult-population-size ratios in wild life - a review. Genetical Research, 66, 95-107.

GAINES, M. S. AND MCCLENAGHAN, L. R. 1980. Dispersal in small mammals. Ann. Rev. Ecol. Syst., 11, 163-196.

GOCKEL, J., HARR, B., SCHLOETTERER, C., ARNOLD, W. ET AL. 1997. Isolation and characterisation of microsatellite loci from Apodemus flavicollis (Rodentia, Muridae) and Clethrionomys glareolus (Rodentia, Cricetidae). Mol. Ecol., 6, 597-599.

GOLDSTEIN, D. B. AND SCHLÖTTERER, C. 1999. Microsatellites: Evolution and Applications. Oxford University Press.

GOUDET, J. 1995. FSTAT (vers. 1.2): a computer program to calculate F-statistics. J. Hered., 86, 485-486.

GRÖNLUND, E. AND MELANDER, O. (eds) 1995. Swedish-Russian Tundra Ecology-Expedition-94, A Cruise Report. Swedish Polar Research Secretariat, Stockholm.

HARDY, O. J. AND VEKEMANS, X. 1999. Isolation by distance in a continuous population: reconciliation between spatial autocorrelation analysis and population genetic models. Heredity, 83, 45-154.

HEDRICK, P. W. 1999. Perspective: Highly variable loci and their interpretation in evolution and conservation. Evolution, 53, 313-318.

ISHIBASHI, Y., SAITOH, T., ABE, S. AND YOSHIDA, M. C. 1997a. SeXrelated kin structure in a spring population of grey-sided voles Clethrionomys rufocanus as revealed by mitochondrial and microsatellite DNA analysis. Mol. Ecol., 6, 63-71.

ISHIBASHI, Y., SAITOH, T., ABE, S. AND YOSHIDA, M. C. 1997b. Cross-species amplification of microsatellite DNA in Old World microtine rodents with PCR. Mammal Study, 22, 5-10.

ISHIBASHI, Y., YOSHINAGA, Y., SAITOH, T., ABE, S. ET AL. 1999. Polymorphic microsatellite DNA markers in the field vole Microtus montbelli. Mol. Ecol., 8, 163-164.

KIMURA, M. AND WEISS, G. H. 1964. The stepping stone model of population structure and the decrease of population genetic correlation with distance. Genetics, 49, 561-576.

KNUTSEN, H., RUKKe, B. A., JORDE, P. E. AND IMS, R. A. 2000. Genetic differentiation among populations of the beetle Bolitophagus reticulatus (Coleoptera: Tenebrionidae) in a fragmented and a continuous landscape. Heredity, 84, 667-674.

KUMAR, S., TAMURA K. AND NEI M. 1993. MEGA: Molecular Evolutionary Genetics Analysis, Version 1.01. Pennsylvania State University, Pennsylvania, PA, USA.

LEBLOIS, R., ROUSSET, F., TIKEL, D., MORITZ, C. AND ESTOUP, A. 2000. Absence of evidence for isolation by distance in an expanding cane toad (Bufo marinus) population: an individual-based analysis of microsatellite genotypes. Mol. Ecol., 9, 1905-1909.
MANTEL, N. 1967. The detection of disease clustering and a generalized regression approach. Cancer Res., 27, 209-220.

MILlER, S. A., DYKeS, D. D. AND POLESKY, H. F. 1988. A simple salting procedure for extracting DNA from human nucleated cells. Nucl. Acids Res., 16, 215.

MOTRO, U. AND THOMSON, G. 1982. On heterozygosity and the effective size of populations subject to size changes. Evolution, 36, 1059-1066.

NEI, M. 1987. Molecular Evolutionary Genetics. Columbia University Press, New York.

ORLOV, v. A. 1980. Seasonal migration of Siberian and collared lemmings in the typical tundra subzone on Taimyr. In: Regulation Mechanisms of Lemming and Vole Densities in the Far North, pp. 95-99. DVNC AN SSSR, Vladivostok (in Russian)

RAYMOND, M. AND ROUSSET, F. 1995. GENEPOP (v. 1.2): population genetics software for exact tests and ecumenism. J. Hered., 86, 248-249.

ROUSSET, F. 1997. Genetic differentiation and estimation of gene flow from $F$-statistics under isolation by distance. Genetics, 145, 1219-1228.

ROUSSET, F. 2000. Genetic differentiation between individuals. J. Evol. Biol., 13, 58-62.

SCHNEIDER, S., KUEFFER, J. M., ROESSLI, D. AND EXCOFFIER, L. 1997. ARLEQUIN. A software for population genetic data analysis, version 1.1. Genetics and Biometry Laboratory, Department of Anthropology, University of Geneva, Switzerland.

SDOBNIKOv, v. M. 1957. Lemmings on Northern Taimyr. Trudy Arctic Res. Inst., 205, 109-125. (in Russian)

SLATKIN, M. 1993. Isolation by distance in equilibrium and nonequilibrium populations. Evolution, 47, 264-279.

SMOUSE, P. E. AND PEAKALL, R. 1999. Spatial autocorrelation analysis of individual multiallele and multilocus genetic structure. Heredity, 82, 561-573.

STENSETH, N. C. AND IMS, R. A. (eds) 1993. The Biology of Lemmings. Academic Press, London.

STEWART, W. A., PIERTNEY, S. B. AND DALLAS, J. F. 1998. Isolation and characterisation of highly polymorphic microsatellites in the water vole, Arvicola terrestris. Mol. Ecol., 7, $1258-1259$.

TEMPleton, A. R., CRANDAll, K. A. AND Sing, C. F. 1992. A cladistic analysis of phenotypic associations with haplotypes inferred from restriction endonuclease mapping and DNA sequence data. III. Cladogram estimation. Genetics, 132, 619-633.

UNDERHILL, L. G., PRYS-JONES, R. P., SYROECHKOVSKI, E. E. JR, GROEN, N. M. ET AL. 1993. Breeding of waders (Charadrii) and Brent Geese Branta bernicla bernicla at Pronchisheva Lake, Northeastern Taimyr, Russia, in a peak and a decreasing lemming year. Ibis, 135, 277-292.

VAN STADEN, M. J., MICHENER, G. R. AND CHESSER, R. K. 1996. Spatial analysis of microgeographic structure in Richardson's ground squirrels. Can. J. Zool., 74, 1187-1195.

WASER, P. M. AND STROBECK, C. 1998. Genetic signatures of interpopulation dispersal. Trends Ecol. Evol., 13, 43-44.

WRIGHT, s. 1943. Isolation by distance. Genetics, 28, 139-156. 


\section{Appendix 1}

Absolute frequencies of mtDNA $C R$ haplotypes observed in Lemmus sibiricus at each locality and sample size $(n)$. The small scale transect is presented as one locality $(11 \mathrm{~km})$

\begin{tabular}{|c|c|c|c|c|c|c|c|c|c|c|c|c|c|c|c|c|}
\hline \multirow[b]{2}{*}{ Haplotypes } & \multicolumn{15}{|c|}{ Locality } & \multirow[b]{2}{*}{ Total } \\
\hline & 1 & 2 & 3 & 4 & 5 & 6 & 7 & $11 \mathrm{~km}$ & 8 & 9 & 10 & 11 & 12 & 13 & 14 & \\
\hline 10 & 3 & 5 & 1 & 3 & & 1 & 3 & 16 & & 2 & 1 & 3 & 2 & 3 & 6 & 49 \\
\hline 13 & & 1 & & & 1 & 1 & & 3 & & 4 & & & & & & 10 \\
\hline 90 & & 2 & & & 1 & 5 & & 19 & 2 & & & & & & & 29 \\
\hline 86 & & 1 & 3 & & & & & & & & & & & & & 4 \\
\hline 70 & & 1 & & 1 & & & & & & & & & & & & 2 \\
\hline 81 & & & 1 & 2 & & 2 & & & & & & & & 9 & & 14 \\
\hline 1 & & & & 2 & & & 2 & 2 & 1 & 3 & & 4 & 3 & & 2 & 19 \\
\hline 59 & & & & 2 & & 1 & 1 & 10 & & & & & & & & 14 \\
\hline 650 & & & & 1 & & 5 & & 5 & & & & & & & & 11 \\
\hline 25 & & & & & 1 & & 1 & 25 & 4 & & 1 & & 3 & & 1 & 36 \\
\hline 7 & & & & & 1 & & & 1 & & 1 & & & 1 & & & 4 \\
\hline 470 & & & & & & 1 & & 1 & & & & 5 & & & & 7 \\
\hline 49 & & & & & & & 1 & 15 & 1 & & 4 & & & & & 21 \\
\hline 61 & & & & & & & 2 & 8 & & & & & & & & 10 \\
\hline 6 & & & & & & & & 17 & 5 & 11 & & & & & & 33 \\
\hline 52 & & & & & & & & & 1 & & & & & 3 & 3 & 7 \\
\hline 116 & & & & & & & & & 1 & & & & 3 & & & 4 \\
\hline 674 & & & & & & & & 5 & & & & & & & & 5 \\
\hline 96 & & & & & & & & 2 & & & 11 & & & & & 13 \\
\hline 131 & & & & & & & & & & & & & 4 & 1 & & 5 \\
\hline 55 & & & & & & & & & & & & 1 & & & & 1 \\
\hline 155 & 3 & & & & & & & & & & & & & & & 3 \\
\hline 156 & 2 & & & & & & & & & & & & & & & 2 \\
\hline 157 & 2 & & & & & & & & & & & & & & & 2 \\
\hline 159 & 3 & & & & & & & & & & & & & & & 3 \\
\hline 160 & 1 & & & & & & & & & & & & & & & 1 \\
\hline 166 & 1 & & & & & & & & & & & & & & & 1 \\
\hline 147 & & 2 & & & & & & & & & & & & & & 2 \\
\hline 148 & & 1 & & & & & & & & & & & & & & 1 \\
\hline 150 & & 1 & & & & & & & & & & & & & & 1 \\
\hline 152 & & 1 & & & & & & & & & & & & & & 1 \\
\hline 82 & & & 2 & & & & & & & & & & & & & 2 \\
\hline 84 & & & 1 & & & & & & & & & & & & & 1 \\
\hline 69 & & & & 1 & & & & & & & & & & & & 1 \\
\hline 71 & & & & 3 & & & & & & & & & & & & 3 \\
\hline 330 & & & & & & & & 2 & & & & & & & & 2 \\
\hline 432 & & & & & & & & 3 & & & & & & & & 3 \\
\hline 434 & & & & & & & & 2 & & & & & & & & 2 \\
\hline 298 & & & & & & & & 2 & & & & & & & & 2 \\
\hline 247 & & & & & & & & 1 & & & & & & & & 1 \\
\hline 315 & & & & & & & & 1 & & & & & & & & 1 \\
\hline 14 & & & & & & & & & & 3 & & & & & & 3 \\
\hline 533 & & & & & & & & & & & & 1 & & & & 1 \\
\hline 535 & & & & & & & & & & & & 2 & & & & 2 \\
\hline 122 & & & & & & & & & & & & & 1 & & & 1 \\
\hline 126 & & & & & & & & & & & & & 1 & & & 1 \\
\hline 128 & & & & & & & & & & & & & 1 & & & 1 \\
\hline 610 & & & & & & & & & & & & & & & 3 & 3 \\
\hline 615 & & & & & & & & & & & & & & & 1 & 1 \\
\hline$n$ & 15 & 15 & 8 & 15 & 4 & 16 & 10 & 140 & 15 & 24 & 17 & 16 & 19 & 16 & 16 & 346 \\
\hline
\end{tabular}

(c) The Genetics Society of Great Britain, Heredity, 86, 716-730. 


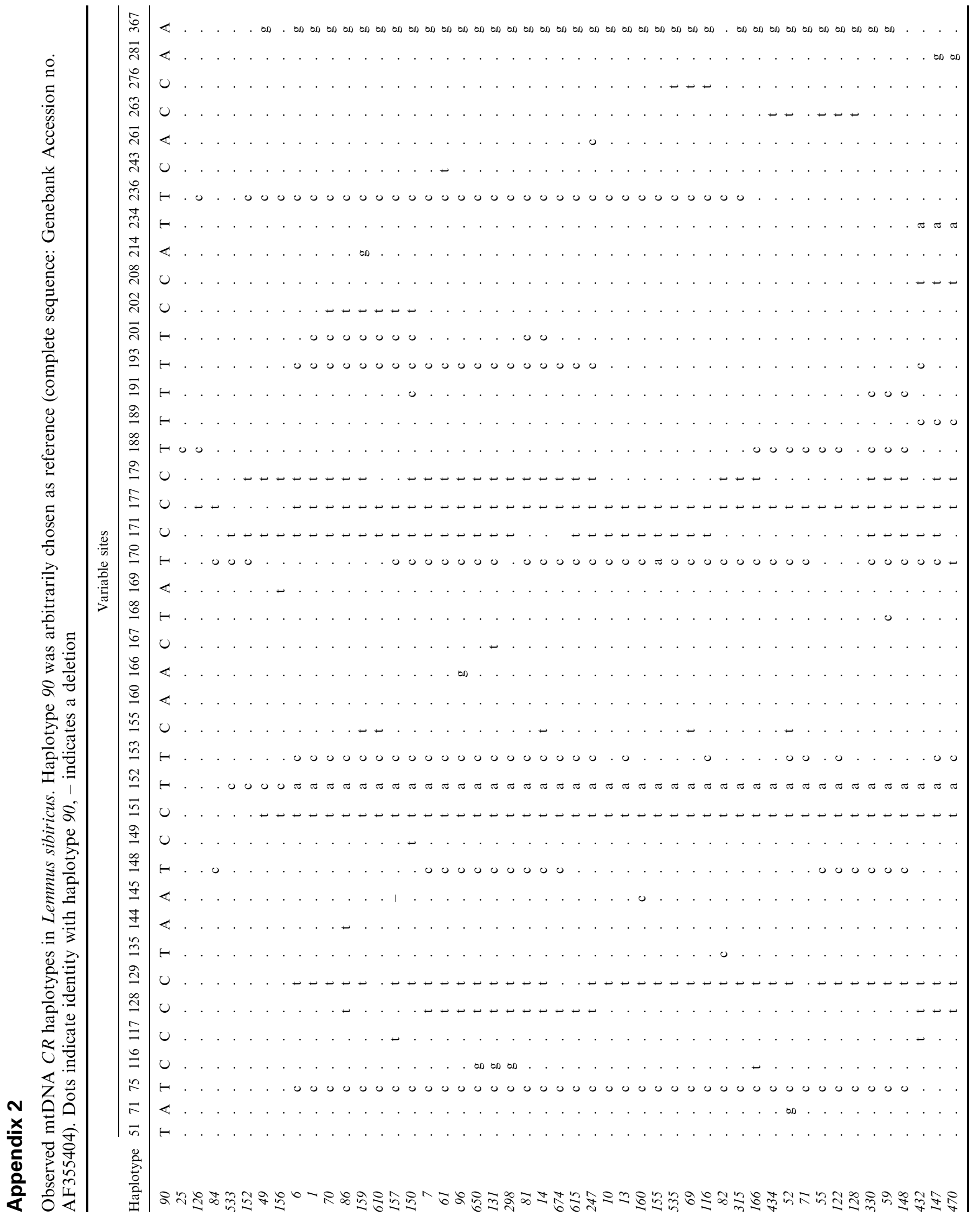

(C) The Genetics Society of Great Britain, Heredity, 86, 716-730. 